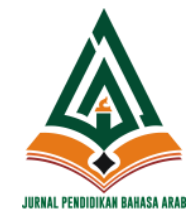

\author{
Alibbaa': Jurnal Pendidikan Bahasa Arab \\ Vol. 1 No. 2, Juli 2020 \\ P-ISSN: 2721-1606 | E-ISSN: 2716-4985 \\ doi: https://doi.org/10.19105/alb.v1i2.3619
}

\author{
Amaliya Sholihah, Ihadatul Hidayah \\ Islamic University of Sunan Kalijaga Yogyakarta, Indonesia \\ Corresponding E-mail: Amaliyasholibab@gmail.com
}

\title{
Pembelajaran Bahasa Arab Dalam Buku Ta'lim Al-'Arabiyah Bi Thoriqoh Haditsah M. Fethullah Gülen
}

\begin{abstract}
The focus of this study is to investigate the thinking of Islamic education figures who have an interest in learning Arabic. This study focuses on a work entitled "Ta'lim Al-" Arabiyyah Bi Tariqah Haditsah ". The significance from this study is how the design made by Gülen in his book for learning Arabic and are there implication and integration of his thinking with learning Arabic. Seeing that Gülen is an Islamic education figure who who concerns with education including Arabic learning. The method of this study is library research, in which the source of the data is taken from several literatures. The approach of this study is the philosophical analysis-thinking of the figure. Gülen's framework is a form of his concern in the world of education one of which was towards learning Arabic. Gülen designs the Arabic language learning model in a learning book called Ta'lim Al- "Arabiyyah Bi Tariqah Haditsah which contains a (modern) hadith model design. In his book, Gülen divides Arabic language learning into three levels, beginner, intermediate and advanced.
\end{abstract}

Keywords: Ta'lim Al-'Arabiyah Thoriqob Haditsah, M.Fethullab Gülen 


\section{Pendahuluan}

Sejak abad pertengahan bahasa Arab menjadi bahasa universal yang akhirnya menjadikannya salah satu dari beberapa bahasa terbesar di dunia seperti Bahasa Yunani, Bahasa Latin, Bahasa Inggris, Bahasa Prancis, Bahasa Spanyol dan Bahasa Rusia. Dan saat ini Bahasa Arab merupakan salah satu bahasa yang dipergunakan untuk menulis dokumen-dokumen Perserikatan Bangsa Bangsa (PBB).

Di sisi lain, Bahasa Arab adalah juga Bahasa Al-Qur'an. Hal inilah yang menjadikan Bahasa Arab menjadi bahasa yang sangat berkaitan dengan Islam, sebab ia adalah Bahasa agama bagi kaum muslim di dunia, baik bagi mereka yang mempergunakan bahasa Arab dalam kehidupan sehari-hari maupun tidak. Bahkan, bahasa Arab adalah salah satu bahasa asing yang paling banyak diajarkan di sekolah-sekolah di Indonesia, baik di kota maupun di pelosok-pelosok desa. Bahasa Arab umumnya diajarkan di madrasah-madrasah dan pondok-pondok pesantren yang tersebar di seluruh wilayah tanah air, mulai dari tingkat sekolah dasar hingga level perguruan tinggi. ${ }^{1}$

Sepak terjang bahasa Arab baik di lembaga formal atau nonformal setidaknya memiliki tujuan besar kenapa harus dipelajari. Pertama, tujuan keagamaan dimana bahasa Arab dipelajari dengan tujuan untuk memahami teks keagamaan (dalam hal ini khususnya di Indonesia adalah mempelajari agama Islam). Kedua, tujuan dalam bidang sosial-komunikatif dimana bahasa Arab dipelajari sebagai alat komunikasi baik aktif ataupun pasif. Karena dianggap bagian terpenting dalam pendidikan khususnya pendidikan islam di Indonesia,

\footnotetext{
${ }^{1}$ https://www.malang-post.com/berita/detail/khazanah-bukubukupembelajaran-bahasa-arab. (Diakses Pada 11 Mei 2020 Pukul 09.30)
} 
bahasa Arab dalam sepak terjangnya tidak lepas dan terus berkembang dari hasil para pemikir tokoh, baik nasional ataupun internasionah

Sudah banyak tokoh-tokoh baik nasional atau internasional berusaha keras dalam mengembangkan pembelajaran bahasa Arab. KH. Imam Zarkasyi dan H. D Hidayat salah satunya merupakan tokoh nasional di Indonesia yang memberi perhatian pada bahasa Arab. Karya-karya dalam bidang pembelajaran bahasa Arab sudah banyak dikaji dalam beberapa penelitian yang terkait dengan pendidikan islam khususnya bahasa Arab. Ada tokoh lain yang memberi sumbangan besar atas perhatiannya untuk mengembangkan pembelajaran bahasa Arab ke arah yang lebih maju. ${ }^{2}$

Salah satu tokoh masa kini yang memberi perhatian besar pada bahasa Arab untuk kemajuan adalah M. Fethullah Gülen, kelahiran darah Turki yang memiliki gagasan-gagasan yang sudah banyak diterima di kalangan tokoh dunia. Menarik untuk diteliti, jika seorang yang berlatang belakang ulama, ahli tafsir, sufi, pemikir bahkan seorang penyair mempunyai perhatian besar dalam bidang pendidikan. Bahkan perhatian tersebut bukan sebatas teoritis yang ditulis namun aksi nyata yang aplikatif. ${ }^{3}$

Di sela kesibukan Gulen sebagai tokoh sekaligus pelayan masyarakat di Turki, dengan semangat beliau menulis buku pelajaran bahasa Arab yang berjudul Al-‘Arabiyah Bi Thariqoh Haditsah (pembelajaran bahasa Arab dengan metode baru) sebanyak 5 Jilid, 2

${ }^{2}$ Syukur Prihantono. "Integrasi Pembelajaran Bahasa Arab dengan NilaiNilai Akhlak". Tesis Pasca Sarjana Pendidikan Bahasa Arab UIN Sunan Kalijaga. 2016: 27.

${ }^{3}$ Sehat Ihsan Shadiqin, "Islam dan Modernitas dalam Pandangan Fethullah Gulen”, Substantia Jurnal Ilmu-Ilmu Ushuluddin, Vol. 14 No. 1, 2012: 98-111. 
jilid untuk tingkat pemula, 2 jilid untuk pembelajar menengah dan 1 jilid untuk tingkat lanjut. Gülen merancang gagasan yang disajikan dalam bentuk materi pembelajaran. Penulis menemukan satu perbedaan dalam buku yang Gülen susun. Konsep pemikiran Gülen yang lebih mengutamakan iman, tauhid, cinta, toleransi dan moral sangat kental dengan pemilihan susunan materi yang dipilih. Selain itu kaya akan sarat nilai-nilai akhlak yang dapat diintegrasikan dalam kehidupan sehari hari. Dengan mempelajari karyanya dalam buku Ta'lim Al"Arabiyyah Bi Tariqah Haditsah diharapkan dapat sekaligus pembentukan nilai-nilai pada peserta didik. ${ }^{4}$

Mengkaji pemikiran tokoh, dalam penelitian ini adalah $\mathrm{M}$. Fethullah Gülen, harapan besar menjadi konsep dan pijakan awal untuk dapat memproduksi gagasan dan menciptakan pendidikan Islam khususnya yang ideal dan memiliki daya saing yang tinggi di kancah masyarakat. Gagasan tersebut dengan keterkaitan dalam bahasa Arab, tidak menutup kemungkinan untuk menjadi usulan dan bahan pertimbangan bagi rancangan pembelajaran bahasa Arab di Indonesia

Tulisan ini pada dasarnya untuk mendiskripsikan hasil karya pemikiran Gülen tentang pembelajaran bahasa Arab dalam sebuah buku karyanya. Dalam buku itu akan digali latar belakang pembuatan yang melandasi buku itu diciptakan, bagaimana pemikiran Gülen terhadap pembelajaran bahasa Arab dari mulai tingkatan belajar, metode, evaluasi serta implikasi buku tersebut untuk pembelajaran bahasa Arab bagi dunia pendidikan bahasa Arab khususnya di Indonesia. Dengan hadirnya pemikiran Gülen dalam buku tersebut bisa dirumuskan dalam sebuah pertanyaan, mampukah menjadi dobrakan alternatif untuk pembelajaran bahasa Arab?

Yakinlari), 7

${ }^{4}$ M. Fethullah Gulen. Ta'lim Al'Arbiyah Bi Tariqah Haditsah. (Istanbul: Nil 
Dimana letak implikasi dan integrasi pemikiran Gülen dari buk karya nya dengan pembelajaran bahasa Arab?

Telah penulis singgung bahwa pertama-tama tulisan ini akan memaparkan atau mendeskripsikan latar pembuatan buku Ta'lim Al-"Arabiyyah Bi Tariqah Haditsah karya Gülen. Selanjutnya mendiskripsikan bagaimana pembelajaran bahasa Arab dalam buku tersebut sesuai dengan tingkatan pembelajar, metode yang digunakan dalam buku tersebut. Sehingga menemukan benang merah pada satu titik temu buku karya Gülen tersebut memiliki implikasi terhadap pembelajaran bahasa Arab khususnya di Indonesia sebagai sebuah alternatif yang baik.

\section{Metode Penelitian}

Dalam penulisan artikel ini apabila melihat dari jenis penelitiannya, maka penelitian ini menggunakan penelitian kepustakaan atau library research. Dimana, library research adalah sebuah penelitian yang mana data yang dikumpulkan bersifat deskriptifkualitatif dengan mengakses data primer dan sekunder. Adapun sumber primer data ini adalah karya-karya Fethullah Gülen yang dimuat di www.FethullahGülen.com. Sedangkan untuk data sekunder dari berbagai dokumen, artikel, buku, dan hasil penelitian yang berhubungan dengan Fethullah Gülen. Pendekatan penelitian yang digunakan dalam penulisan artikel ini adalah pendekatan analisisfilosofis, dengan mengkaji pemikiran salah satu tokoh yaitu $\mathrm{M}$. Fethullah Gulen dengan karya-karya yang telah dibuatnya. Berbagai sumber dan data yang berkaitan satu sama lain akan dianalisis, kemudian dipetakan dan diambil kesimpulan dalam bentuk deskriptif. 


\section{Paparan Data dan Hasil Penelitian}

\section{A. Latar Belakang Penulisan Buku Ta'lim Al-“Arabiyyah Bi Tariqah Haditsah}

Kegelisahan Akademik yang besar adalah salah satu pemicu terciptanya buku Ta’lim Al-"Arabiyyah Bi Tariqah Haditsah, beberapa sumber menyebutkan buku ini dicetak dan diterbitkan pada tahun 1998-1999, ${ }^{5}$ walaupun sudah selesai kurang lebih 50 tahun lalu. Pada waktu itu di Turki memang belum ada buku-buku penunjang pembelajaran bahasa Arab yang komprehensif.

Dengan demikian hati Gülen tergerak untuk membuat textbook bahasa Arab yang sesuai dengan keadaan masyarakat Turki pada masa itu. Berawal dari kegelisahan Gülen terhadap masyarakat Turki yang kebanyakan adalah orang Islam, mereka mengerjakan rukun Islam seperti sholat dan puasa tetapi kenyataan masih sedikit sekali yang memahami bahasa Arab. Penegasannya bahwa bahasa Arab sangat menunjang untuk memahami ilmu Alam dan ilmu Agama. ${ }^{6}$ Dengan demikian tujuan pembuatan grand Design pembelajaran menurut Gülen adalah memahami ajaran-ajaran islam yang terkandung dalam Al-Quran dan Hadits. ${ }^{7}$

Sudah diketahui oleh kita sebagai umat Islam, bahwa Islam dengan pesan-pesan adalah terwujudnya Islam Rahmatan Lil'alamin. Syarat mutlak bagi seorang yang ingin memahami dan mendalami Islam salah satunya adalah dengan mempelajari bahasa

${ }^{5}$ www.FethullahGülen.com (diakses pada 13 Mei, pukul 09.00)

6 M. Fethullah Gülen, Menghidupkan Iman dengan Mempelajari Tandatanda Kebesaranya (Jakarta: PT Raja Grafindo Persada,2002), 249.

${ }^{7}$ Muhammad Anas Ma'arif. Ma'arif, "Konsep Pemikiran Pendidikan Toleransi Fethullah Gulen", Tribakti: Jurnal Pemikiran Keislaman, Vol. 30 No. 2, 2019: 295-307. 
Arab dengan benar dan baik. Karena karya-karya seperti Fiqh, Usul Fiqh, Tasawuf dan ilmu lainnya sudah jelas termaktub dalam bahasa Arab. Disinilan Gülen menjelaskan kata perkata bagian syarh dalam bukunya dengan disajikan secara komprehensif.

\section{B. Pembelajaran Bahasa Arab Persfektif M. Fethullah Gülen}

Sudah menjadi rahasia umum bagi kaum peneliti bahasa Arab, bahwa desain pembelajaran bahasa Arab yang ditawarkan Gülen pada buku yang beliau beri nama sebagai metode modern (thariqoh Haditsah). Metode ini adalah sebuah dobrakan terhadab metode klasikal yang terjadi pada masa usmaniyyah. Oleh karena itu, inisiatif dan pemikiran Gülen adalah bagaimana menciptakan pembelajaran bahasa Arab yang komunikatif, inovatif akan tetapi tetap mudah apalagi untuk pemula.

Menurut Dell Hymes adalah orang pertama menyuarakan istilah komunikatif sebagai reaksi terhadap Chomsky dalam kompetensi kebahasaan. Menurut Dell Hymes pandanagn Chomsky terlalu sempit hanya terkait Gramatika. Dell Hymes menyatakan penguasaan pemahaman bahasa bukan terpaku sekedar dari aspek gramatikanya saja benar dan salah, melainkan lebih dari itu. Banyak faktor dalam komunikasi untuk aktualisasi pemakaian bahasa yang disebut konteks. ${ }^{8}$

Dalam karyanya ini, Gülen menuliskan materi yang begitu bervariasi yang terdiri dari hiwar, tadzriibat, qowaid dan qira'ah yang semuanya terdiri dari beberapa teks pilihan. Buku karangan Gülen ini tidak bersifat wajib harud dipelajari dan dimiliki setiap sekolah di Turki, dalam artian buku ini dijual bebas ditoko-toko

${ }^{8}$ Imam Syafi'i dalam Ahmad Muradi, Pembelajaran Menulis Bahasa Arab Dalam Presfektif Komunikatif (Jakarta: Kencana, 2015), 22. 
ALIBBAA': Jurnal Pendidikan Bahasa Arab, 1 (2), 2020

buku. Karena tujuan Gülen dalam menulis buku ini adalah untuk memudahkan siapa saja yang ingin belajar bahasa Arab. ${ }^{9}$

Pembahasan dalam artikel ini akan diurai secara rinci menggunakan analisis isi tentang buku karya Gülen yang berupa textbook tersebut. Dalam penjelasan sebelumnya Gülen dengan tujuan dalam membangun pendidikan adalah terbentuknya moralitas yang lebih baik. Maka dalam penyusunan buku bahasa Arab ini kaya sarat dengan nilai-nilai moral sesuai tujuan inti Gülen tersebut.

Apabila kita rinci buku tersebut maka akan menemukan panduan materi kebahasa araban dengan materi yang bergubungan pada pembentukan moral atau akhlak peserta didik. Oleh karena itu upaya dalam mencapai pemahaman tersebut perlu adanya eksplorasi untuk mengurai nilai-nilai moral akhlak yang termuat dalam materi pembelajaran bahasa Arab yang dirancangnya.

1. Pembelajaran Bahasa Arab Tingkat Pemula

Tingkat pemula disini bukan anak-anak kecil (bukan diukur dari usia) melainkan pemula disini adalah siapa saja seorang yang benar-benar baru menegnal bahasa Arab. Materi yang dirancang untyk pemula dalam buku ini temuat dalam jilid 1 dan jilid 2 . Muatan materi untuk pemula dalam jilid 1 dan jilid 2 ini memuat beberapa materi yakni ; kosa kata (mufradat), pengajaran gramatikal meliputi pengenalan kata tujuk, pengajaran jumlah kata (mufrad, mustanna dan jamak), pengajaran muannats dan mudazakkar, pengajaran penggunaan sebagian 'adad dan ma'dud, dan pengajaran teks bacaan.

${ }^{9}$ www.FethullahGülen.com (diakses pada 13 Mei, pukul 12.00) 
ALIBBAA': Jurnal Pendidikan Bahasa Arab, 1 (2), 2020

a. Pengajaran Mufradat

Pengajaran kosa kata ini adlah dasar dalam rancangan buku ini. Kosa kata memang dalam bahasa Asing harus diperkenalkan terlebih dahulu sebelum pengajaran yang lainnya. Dalam bukunya ini Gülen merancang kosa kata lebih visualisasi, dalam artian banyak penjelasan kosa kata dengan gambar. Ada beberapa tahapan yang dalam mengajarkan kosa kata lewat gambar tersebut :

- Menampilkan benda dengan ilustrasi yang menunjukan makna kata

- Menampilkan peragaan tubuh

Pembelajaran materi seperti ini akan tepat apabila menggunakan metode langsung dengan cara guru mengucapkan kalimat bahasa Arab secara berulang dan dituturkan oleh peserta didik. Cara tersebut akan menghasilkan dua keterampilan sekaligus yaitu mendengar dan berbicara.

b. Pengajaran Qowaid (Gramatika)

Seperti yang sudah diketahui tujian pengajaran qowaid adalah untuk menghindari dari kesalahan berbahasa, baik secara lisan dan tulisan. Materi pengajaran qowaid dirancang Gülen dalam bukunya sebagai berikut :

- Kata Tunjuk Isim Isyarah

- Muannats dan mudzakar

- Pengenalan kata sesuai jumlah mufrad, mustanna dan jama' 
ALIBBAA': Jurnal Pendidikan Bahasa Arab, 1 (2), 2020

- Pengenalan kaidahbilangan, hitungan, dan yang dihitung

- Pengenalan pemakaian sebagian huruf

c. Pengajaran membaca

Pengajaran membaca ini menjadi titik pembeda dengan buku lainnya. Lewat teks bacaan Gülen menyisipkan mateeri pengajaran tentang al-Akhlak al-Islamy. Asumsi Gülen bacaan itu mentukan dan mempengaruhi tindak dan pola pikir yang membaca yaitu peserta didik.

2. Pembelajaran Bahasa Arab Tingkat Menengah

Dua keterampilan inti yang ditekankan pada tingkat menengah ini yaitu: pertama, penguasaan kaidah bahasa (gramatika) baik nahwu atau sharafnya. Kedua, keterampilan berbicara (maharah kalam). Semua materi pada tingkatan ini tertulis dalam jilid 3 yang merupakan kelanjutan dari jilid 1 dan jilid 2 . Penulis akan menuliskan beberapa rincian tema dari matei kaidah dan keterampilan berbicara dibawah ini.

a. Tema materi kaidah bahasa Arab

Dibawah ini adalah beberapa tema yang dirancang Gülen untuk kaidah bahasa Arab tingkat menengah :

- Ba'd as-sifat mudzakar dan muannats.

- Dhomir dan Tahsrif madhi, mudhari.

- Sighat at-Tafhdil.

- Al-madi dan Mudhari.

- Isim maushul 
ALIBBAA': Jurnal Pendidikan Bahasa Arab, 1 (2), 2020

- Al-fa'il

- Maf'ul bih

Dan gaya contoh untuk materi-materi diatas berbeda dengan buku-buku yang lainnya. Dalam buku Gülen lebih komunikatif dengan kaya pesan hikmah menjadi pribadi yang bermoral baik.

b. Tema keterampilan berbicara

Dalam materi kemahiran berbicara Gülen merancang dalam bentuk hiwar berupa percakapan langsung antara dua orang atau lebih banyak lagi dalam praktiknya. Sebelumnya Gülen menyiapkan ta'bir sederhana seperti sapaan, menanyakan nama, alamat dan lain-lain. Gülen merancang kurang lebih 27 tema percakapan untuk menunjang kemahiran berbicara sebagai berikut :

- Pertemuan

- Di bandara

- Di kantor penerbangan

- Stasiun kereta

- Menuju hotel

- Di dalam hotel

- Pergi ke pasar

- Pergi dari hotel

- Perjalanan ke pasar

- Di toko pakaian

- Di supermarket

- Di kantor pos 
- Kantor pos umum

- Makanan Turki

- Menanyakan jalan

- Pengatur lalu lintas dan supir

- Petugas perhubungan di kantor lalu lintas

- Dan lain sebagainya.

Tema-tema yang dirancang Gülen dalam keterampilan berbicara dipilih sesuai kondisi. Dalam artian percakapan tersebut sesuai dengan tempat dimana seorang terbiasa menggunakan untuk bertemu dan berkumpul. Sebagai contoh percakapan anatar penjual dan pembeli, murid dan guru, atau sedang berada di fasilitas umum. Sehingga sipembelajar bahasa arab lebih mudah dalam mengaplikasikannya.

3. Pembelajaran Bahasa Arab Tingkat Lanjut

Setelah memiliki dasar bahasa arab dalam pembelajaran pemula dan menengah, disini peserta didik akan melanjutkan pembelajaran puncak dari buku karangan Gülen. Materi yang dirancang bagi tingkat lanjut ini banyak menyelami pesan hikmah dari al-Qur'an dan Hadits untuk menjadikan beberapa teladan yang dapat diambil oleh peserta didik, yang sesuai dengan tujuan Gülen pembelajaran bahasa Arab kaya sarat dengan pesan moral.

Jilid terakhir dari buku ini memang banyak memadukan materi yang berisi unsur-unsur moral yang membentuk akhlak peserta didik dibandingkan jilid sebelumnya. ini adalah salah satu upaya Gülen lewat pembelajaran bahasa Atab bisa 
ALIBBAA': Jurnal Pendidikan Bahasa Arab, 1 (2), 2020

membentuk pendidikan Humanis. Humanis yang terus ditempa secara sistematis agar menjadi manusia seutuhnya. Materi yang dirancang pada tingkat lanjut terbagi menjadi empat bagian sebagai berikut :

- Analisis beberapa ayat al-Qur'an.

- Analisis al-Qur'an perspektif Balaghah.

- Sajian dari beberapa hadits Nabi.

- Kisah sahabat Khalid bin walid dalam berbagai kehidupannya.

Semua materi yang Gülen rancang di tingkat lanjut pada dasarnya memang fokus pada pendalaman akhlak. Gülen menyesuaikan dengan pendidikan humanis memanusiakan manusia yang merupakan inti dari pendidikan. Pembelajaran bahasa Arab lewat Al-Quran dan Hadits ini bentuk usaha Gülen agar pembelajaran bukan sekedar materi yang disampaikan akan tetapi memiliki dampak luar biasa bagi kehidupan peserta didik, terutama dalam bidang moral dan akhlak.

Rancangan materi dalam buku ini adalah salah satu bentuk pencapaian yang berbeda dari Gülen dalam pembelajaran bahasa Arab. Gülen dalam pendidikan benar-benar menaruh perhatian luar biasa dengan cinta dan kasih yang begitu ikhlas. Dengan begitu sangat jelas bahwa Gülen dalam setiap pembelajarannya adalah terbentuknya pendidikan yang tinggi akan nilai akhlak mulia atau sering disebut dengan at-Takhalluq bi akhlaq Allah (berakhlak dengan Akhlak-Akhlak Allah). 


\section{Teknik Evaluasi dalam buku Ta'lim Al-'Arabiyah Bi Thoriqoh}

\section{Haditsah}

Salah satu kriteria baik dalam buku teks pembelajaran adalah adanya alat ukur atau evaluasi yang menunjukan peserta didik mampu mengetahui kompetensi yang telah dicapainya selama proses pembelajaran. ${ }^{10}$ Tingkat pencapaian peserta didik bisa menjadi fedd back apakah harus ada pengulangan aau memperdalam pelajaran atau melanjutkan kepada materi selanjutnya.

Teknik evaluasi bisa dilakukan dalam beberapa cara, salah satunya dengan latihan (tamriinat) pada setiap akhir pelajaran atau bab. Pertanyaan tersebut khusus untuk jawaban tes tulis (khitabah) dan tes lisan (musyafahatan). Jawaban secara tulis bisa meliputi pemahaman terhadam teks, mengurutkan kata, mengganti kata berdasarkan contoh dan memilih kata yang sesuai. Sedangkan jawaban untuk tes lisan bisa dengan cara langsung dari pengajar dan perintah mempraktekan sebuah percakapan.

Ada sisi lain yang penulis sampaikan perbedaan pada evaluasi yang ada dalam buku teks Gülen ini dari segi model pertanyaan yang disampaikan dalam bukunya. Karena tujuan dasar dari penyusunan buku bahasa arab ini adalah terbentuknya moral baik pada peserta didik, selain mencantumkan materi tentang penanaman nilai akhlak maka model pertanyaan berkaitan dengan moral atau akhlak. Contoh pertanya-petanyaan Gülen diantaranya:

$10 \mathrm{https} / / /$ eurekapendidikan.com/kriteria-buku-teks-pelajaran (diakses pada 13 Maret pukul 12.00) 
1. Menanyakan aktifitas keseharian (berapakali membaca surat al-Fatihah dan lainnya)

2. Menghitung sifat dan menghitung sifat tersebut yang ada pada diri peserta didik.

3. Menanyakan tujuan penciptaan manusia.

4. Bertanya tentang hormat kepada orang tua dengan mencontoh nabi-nabi.

Dan pertanyaan-pertanyaan lain yang menyangkut dengan akhlak atau moral. Menurut pandangan penulis, sekilas jarang muncul model pertanyaan tersebut dalam pembelajaran bahasa Arab dalam buku teks lainnya. Penulis mengambil kesimpulan dengan model pertanyaan tersebut Gülen menginginkan peserta didik lebih menjiwai dan tidak sebatan knowlage saja. Maka dari itu Gülen terbukti tidak sebatas mengajar melainkan mendidik, mengajak peserta didik muhasabah atau intropeksi pada dirinya sendiri, menuntun pada yang haqq.

\section{Implikasi Pemikiran M. Fethullah Gülen Terhadap}

\section{Pembelajaran Bahasa Arab Di Indonesia: Sebagai Alternatif}

Telah penulis singgung di atas landasan filosofis pembelajaran bahasa arab bukan dalam KMA tahun 2019 adalah sebagai alat komunikasi dan untuk mampu memahami ajaran pendidikan islam yang termaktub dalam Al-Qur'an dan Hadits. Bahasa Arab pada hakikatnya mendorong pembelajar pada kemampuan reseptif dan produktif. Kemampuan reseptif memiliki arti bahwa dirinya mampu memahami dan mengerti bacaan dan pembicaraan orang lain dalam bahasa arab. Sedangkan kemampuan produktif adalah 
ALIBBAA': Jurnal Pendidikan Bahasa Arab, 1 (2), 2020

kemampuan diri seorang menggunakan bahasa Arab sebagai alat komunikasi (berbicara) dan kemampuan menulis bahasa Arab. ${ }^{11}$

Sudah diketahui bahwa pembelajaran bahasa Arab meliputi empat keterampilan dalam prosesnya, keterampilan berbicara, keterampilan mendengar, keterampilan membaca dan keterampilan menulis.beberapa pakar juga menyisipkan keterampilan lainnya dalam pembelajaran bahasa Arab seperti gramatika yang dianggap penting untuk memahami teks bahasa Arab baik dari nahwu dan shorof agar terhindar atau meminimalisir kesalahan berbahasa Arab.

Gülen dalam pendapatnya menyatakan bahwa dalam setiap mata pelajaran harus disisipkan nilai-nilai karakter spiritual dalam prosesnya. Tak ketinggalan bahasa Arab yang di Indonesia khususnya sudah dianggap sebagai bahasa agama harus demikian juga. Cara penyampaian dalam penanaman nilai-nilai tersebut bisa secara lisan atau tulisan, bahkan dengan tindakan seseorang yang disebut guru atau pendidik yang menanamkannya melalui materi dalam pembelajaran. Tujuannya adalah bukan sekedar menyampaikan teori-teori, melainkan membentuk karakter peserta didik yang bermoral baik dengan harapan mempunyai generasi yang menjunjung tinggi moral akan terbentuk tatanan masyarakat yang harmonis, saling menghormati, menghargai, dan mempunyai kepedulian sosial yang tinggi.

Fenomena sekarang masyarakat kita khusus dalam dunia pendidikan telah sangat kehilangan nilai karakter pada setiap siswa atau peserta didik. Banyak kejadian-kejadian seperti tawuran,

${ }^{11}$ Keputusan Menteri Agama Nomor 183 Tahun 2019. 
bulliying salah satunya yang mengikis nilai karakter dalam lingkup ini. Semua upaya telah dikerahkan dalam prencanaan pembelajaran untuk membentuk karakter siswa. Nilai karakter yang dimaksud tidak akan terlepas dari mengarah pada hal kebaikan, salah satu contohnya adalah seperti cinta tanah air,tanggung jawab, kerjasama, relijius dan nilai baik yang lainnya.

Nilai karakter diatas harus diimbangi dengan sosok pendidik yang mempunyai kualitas dan kuantitas nilai yang memadai. Dalam hal ini berarti mampu memaduka pendidikan umum dan spiritual dalam proses pembelajarannya. Kecintaan Gülen dan perhatian dalam keilmuan islam terbukti dalam menanamkan nilai luhur yang terkandung dalam dua pedoman besar yakni al-Qur'an dan Hadits. Sehingga pemikiran yang ia rancang dan susun dalam pembelajaran bahasa Arab tidak lepas dari al-Quran dan Hadits. Maka dari itu pemikiran dalam pembelajaran bahasa Arab mempunyai relevansi kuat karena bersumber dari sumber yang hebat.

Pemahaman bahasa Arab yang kuat akan menjadi bekal untuk memahami dan mengkaji kedua sumber islam tersebut. Dengan konsistensi menjelaskan kaidah-kaidah dengan contoh dari ayat alQur'an dan potongan hadits . bukan sekedar menyebutkan arti kata, Gülen menambahkan penjelasan yang diambil dari pendapat sendiri atau orang lain. Bahasa Arab memberi sumbangan besar diranah sosial dengan terus melakukan pendalam materi al-Qur'an dan Hadits dalam pembelajaran bahasa Arab. Karena fenomina sekarang yang menjadi rusak tatanan sosial seperti saling 
ALIBBAA': Jurnal Pendidikan Bahasa Arab, 1 (2), 2020

mengkafirkan, radikalitas adalah disebabkan kuran memahami bahasa Arab secara utuh untuk memahami dalil-dalil yang ada.

Melihat salah satu wacana tersebut, penulis berpandangan bahwa pembelajaran khususnya pembelajaran bahasa Arab di perguruan tinggi perlu halnya melakukan rekontruksi ke arah produktif. Salah satunya dengan membuat beberapa konsentrasi dalam pembelajarannya. Dapat dicontohkan konsentrasi terjemah, menulis, berbicara dan konsentrasi lainnya yang lebih produktif dalam pembelajaran bahasa Arab. Sehingga hasil yang didapat dari kegiatan pembelajaran bahasa Arab tidak lagi terkesan setengahsetengah atau kurang maksimal.

Baik sekolah maupun perguruan tinggi sudah seharusnya pula memanfaatkan kemajuan teknologi dan media pada zaman sekarang. Dalam arti lain perlu penataan ulang sistem pembelajaran bahasa Arab yang berbasis teknologi pendidikan modern. Salah satu cara yang ditawarkan dengan melakukan inovasi dalam kurikulum pembelajaran bahasa Arab, adanya pelatihan-pelatihan yang ekstra untuk para pendidik bahasa Arab baik guru maupun dosen, serta metode dan pendekatan pembelajaran yang terus di upgrade kearah yang lebih modern. Dengan harapan pendidikan dan pembelajaran bahasa Arab lebih terarah pada kemajuan yang lebih baik.

\section{E. Refleksi Metode Pembelajaran Bahasa Arab M. Fethullah Gülen}

Melihat bahwa buku Ta'lim Al-"Arabiyyah Bi Tariqah Haditsah sudah dibuat beberapa tahun lalu, maka sudah tidak asing 
ALIBBAA': Jurnal Pendidikan Bahasa Arab, 1 (2), 2020

bahwa akan terdapat kekurangan dan kelebihan masing-masing. Buku tersebut tentu tidak akan lepas dari sosio-historis di Turki pada masa itu. Bahasa arab yang memang belum memiliki tempat strategis hasil dari kebijakan pemerintahan yang mengakibatkan masyarakat sangat asing terhadap bahasa Arab. Level cukup bagi masyarakat Turki adalah mengajarkan bahasa Arab dengan kadar yang cukup sederhana. Melihat urutan materi dari tingkat pemula sampai tingkat lanjut di buku

Sudah penulis singgung layaknya karya pasti memiliki kekurangan dan kelebihan. Kekurangan yang terlihat adalah urutan materi dari mulai tingkatan pemula menuju tingkatan yang selanjutnya dari buku bahasa Arab karya Gülen adalah kurang memperlihatkan aspek dari segi kesesuaian. Salah satu dapat diambil contoh dalam hal kosa kata, Gülen hendaknya menyediakan kolom untuk penjelasan dengan bahasa Ibu (Turki). Karena pada dasarnya dalam menyusun buku teks ajar harus sesuai dengan psikologi belajar dan hirarki mengajarkan.

Selanjutnya, sebaiknya dalam sajian atau gambaran materi itu menentukan satu metode pengajaran. Apabila terpaku dengan corak yang Gülen tulis dalam bukunnya, otomatis guru atau pendidik akan mengacu pada satu metode saja, yaitu metode ceramah.

Kelebihannya, terlepas daru segara kekurangan gambar meteri yang Gülen tulis dan cara penulisannya ini sangat cocok dalam membantu membentuk karakter peserta didik. Bukan sekedar materi yang hendak menjadi pengetahuan belaka akan tetapi menjadi pembentukan karakter kuat bagi peserta didik. 


\section{Kesimpulan}

M.Fethullah Gülen seorang pakar dalam dunia pendidikan islam dengan segudang karya-karyanya memiliki perhatian lebih juga terhadap dunia pembelajaran bahasa Arab. Salah satu bukti perhatian beliau adalah dengan disusunnya text bahasa Arab yang berjudul Ta'lim Al-“Arabiyyah Bi Tariqah Haditsah. Buku ini adalah salah satu karya Gülen dalam bidang bahasa Arb sebagai sumbangan dan kontribusi terhadap pembelajaran bahasa Arab dengan tujuan pembelajaran yang didalamnya memuat kandungan pembelajaran moral untuk peserta didik agar tidak hanya sebatas pengetahuan bahasa Arab akan tetapi ada nilai-nilai moral yang terkandung didalamnya.

Rancangan pembelajaran bahasa Arab Gülen adalah melalui pendekatan modern. Dalam rancangannya Gülen membagi tingkatan pembelajar bahasa Arab kedalam tiga tingkatan. Pembelajaran tingkat pemula sebagai dasar dengan materi yang dirancang adalah mnegetahui kosa kata yang divisualisasikan, teks sederhana, dan gramatika bahasa. Tingkat pembelajar menengah berpusat pada dua kemahiran yakni kemahiran berbicara dengan konsep memperbanyak percakapan, dan kemahiran kaidah bahasa yang diperdalam. Selanjutnya tingkat pembelajar lanjut, rancangan 
ALIBBAA': Jurnal Pendidikan Bahasa Arab, 1 (2), 2020

yang dibuat Gülen adalah pemahaman-pemahaman terhadap ayat al-Quran dan hadits pilihan serta kisah teladan. 


\section{Daftar Pustaka}

Al-Kumsyi, Sulaiman. Percikan Pemikiran Ulama Besar Muhammad Fethullah Gulen. Semarang: INSISMA, 2014.

Arsyad, Azhar. Bahasa Arab dan Metode Pengajaranya. Yogyakarta: Pustaka Pelajar, 2010.

Bakker, Anton dan Achmad Charris Zubair. Metodologi Penelitian Filsafat. Yogyakarta: Penerbit Kanisius,1990.

Choir, Gulen. Mengenal Sosok Fethullah Gulen. Jakarta: Uin Syarif Hidayatullah, 2013.

Gulen, M. Fethullah. Ta'lim Al-'Arabiyyah Bi Tariqah Haditsah. Istanbul: NIL YAKINLARI,1999.

John W. Creswell. Research Design: Pendekatan Kualitatif, kuantitatif dan Mixed. Yogyakaera: Pustaka Pelajar, 2014.

KMA 183 Tahun 2019

Langgulung, Hasan. Beberapa Pemikiran Tentang Pendidikan Islam. Banndung: al-Ma'arif, 1980.

Makruf, Imam. Strategi Pembelajaran Bahasa Arab Aktif. Semarang: Needs Press, 2009.

Nurani, Qoim. "Pemikiran Tammam Hassan Tentang Pembelajaran Nahwu Dan Relevansinya Terhadap Pembelajaran Qiraah Di Madrasah" Skripsi, Fakultas Ilmu Tarbiyah dan Keguruan, UIN Sunan Kalijaga, 2015.

Rahmayani, Savira. "Fethullah Gulen Sebagai Tokoh Sentral Dalam Gerakan Fethullah Gulen" Skripsi, Fakultas Ilmu Budaya Studi Arab, Universitas Indonesia, 2011.

Prihantoro, Syukur. "Integrasi Pembelajaran Bahasa Arab dengan NilaiNilai Akhlak ", Tesis, Fakultas Ilmu Tarbiyah dan Keguruan, UIN Sunan Kalijaga, 2016.

Prihantono, Syukur. "Pengajaran Nilai-Nilai Akhlak Islam Dalam Buku Ta"Lim Al-'Arabiyah Bi Tariqah Haditsah Karya M. Fethullah Gulen" Jurnal Ilmiah Didaktika, Vol. 19, No. 1, Agustus 2019 16-33.

Sahin, Ali. Pemikiran M. Fethullah Gulen Dalam Pendidikan Islam. Skripsi, Fakultas Ilmu Tarbiyah dan Keguruan, UIN Syarif Hidayatullah, 2014. 
ALIBBAA': Jurnal Pendidikan Bahasa Arab, 1 (2), 2020

Stefan Titscher, dkk. Metode Analisis Teks \& Wacana. Yogyakarta: Pustaka Pelajar, 2009.

Sugiyono. Metode Penelitian Kuantitatif, Kualitatif, dan R\&D. Bandung: Alfabeta, 2013.

Wahyudin, dan Fathur Rohman. "Konsep Pendidikan Islam IntegratifInterkonektif Persfektif Kitab Wadhaif Al-Muta'allim". Jurnal studi Keislaman Al-Hikmah, Vol. 7, No. 1, Maret 2017.

https://www.malang-post.com

www.FethullahGulen.com 